\title{
Occupational Identities and Physical Exertion in (re)configurations of New Technologies in Eldercare ${ }^{1}$
}

I Jeppe Zielinski Nguyen Ajslev ${ }^{2}$

Senior researcher, the National Research Centre for the Working Environment, Denmark

I Helene Højbjerg Johansen

Research assistant, the National Research Centre for the Working Environment, Denmark

I Malene Friis Andersen

Post doc. the National Research Centre for the Working Environment, Denmark

I Otto Melchior Poulsen

Retiree head of research, the National Research Centre for the Working Environment, Denmark

I Lars Louis Andersen

Professor, the National Research Centre for the Working Environment, Denmark

\begin{abstract}
New technologies are perceived as a solution to the rising proportion of people requiring elderly care across the Nordic countries. Implementing technologies has unforeseen consequences for the content of work and the working environment. This interview-based study within Danish elderly care investigates the consequences of physical exertion for the work and occupational identities of care workers. Through analytical framework integrating positioning theory and agential realism, the study shows that new technologies in certain constellations may further synergies between the reduction of physical exertion and occupational identities, and in others may harm this relation. The study contributes to empirical knowledge about implementing technologies and to discussions of moral literacy and workarounds within care work by suggesting that the ability to openly judge and question physical and ethical consequences of employing technologies is a valuable competence for care workers and, in addition, that furthering these competences is a challenge for managers and legislators.
\end{abstract}

\section{KEYWORDS}

Elderly care / ethics / health care / identity / musculoskeletal disorders / occupational health and safety / physical exertion / science and technology studies / technology

\section{Introduction}

emographic changes toward an increased proportion of elderly in the population and a slightly declining percentage of people active in the labor market toward 2040 (Danmarks Statistik 2017) is leading to an increasing percentage of the

\footnotetext{
${ }^{1}$ You can find this text and its DOI at https://tidsskrift.dk/njwls/index.

${ }^{2}$ Corresponding author: Jeppe ZN Ajslev, the National Research Centre for the Working Environment, Lersø Parkallé 105, 2100 Copenhagen Ø E-mail: jza@nfa.dk.
} 
Danish population requiring elderly care. This presents a challenge to the welfare system as a cause of increasing costs and difficulty in recruitment of qualified workforce in elderly care-a challenge that is echoed throughout the Nordic countries (Kamp et al. 2019; Modig 2012; NOU 2011:11). At the same time, the physically demanding work in elderly care is a significant health and safety problem among care workers (Andersen et al. 2012; NFA, 2014; 2016) and a hindrance to keeping workers active for longer. To create sustainable solutions to these challenges, increasing the use of welfare technologies is perceived politically as attractive. Welfare technologies aimed at assisting care workers in manual tasks (assistive devices)—such as person lifts, washing toilets, and electronic beds-have been widely sought implemented at a political level in both Denmark and the other Nordic countries, with ambitions for increasing the self-reliance of elderly patients, the efficiency of work, and at the same time decreasing physical exertion among elderly care workers. In Denmark, this implementation was manifested through a political agreement between Local Government Denmark (LGDK) and the Danish municipalities. It was estimated that the increased use of ' 2 to 1 ' - a concept consisting of different technologies such as person lifts, turning sheets, electronic beds, etc., that allowed care workers to transfer patients alone, make use of eating robots, and washing toilets-would save 500 million DKK (approx. 67 million euros) over the three years 2014-2016. This economic goal was achieved (Local Government Denmark 2017). Nevertheless, recent years have shown no reductions in the number of care workers suffering from musculoskeletal disorders (MSDs) or pain (NFA 2016). As such, it appears that introducing new technologies aimed at reducing physical exertion have had little effect, even though earlier studies show that employing these have positive effects on physical exertion and the risks for MSD (Andersen et al. 2014).

However, it is likely that the political intention to implement technology does not equal practical usage in care work. While studies considering technologies aimed at reducing physical exertion in care work are scarce, the ones that have been conducted have been unable to produce significant positive results (Verbeek et al. 2012). Jakobsen et al. (2016) suggest that 'the absence of effects may be due to too simplistic models of health behavior change, assuming that the information provided in the intervention by itself leads to a change in knowledge, attitudes or skill' (p. 502). Jakobsen et al.'s point may hold some wisdom, since the implementation of new technologies is more complex than simply providing information or technologies. Oftentimes, new technologies interact with work identities, skills, and roles in different ways than expected when brought to use in a professional context, for instance because employees resist using them, as they do not fit with organizational values or because their design does not fit their purpose (Greenhalgh et al. 2004; Grint \& Woolgar 2007). Therefore, it is necessary to delve into what happens when technologies are implemented in elderly care.

While we are not familiar with qualitative studies of technologies aiming at reducing physical exertion in elderly care, several in-depth qualitative studies have assessed the usage of other new technologies and the ways in which these work, along with occupational identity and the practice of performing care work. There may likely be insights to gather from these studies of other technologies within the same field of work. In particular, information and communication technologies implemented in care work have been the subject of scientific scrutiny (Bergschöld 2018; Clark \& Thompson 2015; Dupret 2017; Dupret \& Friborg 2018; Halbesleben et al. 2010; Krøjer \& Dupret 2015). Common for these studies is a focus on the ways in which technologies contribute to

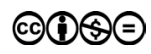


(re)configurations of occupational identities, meaning in work, and care ethics. For instance, Clark and Thompson (2015) show how employees in the health care sector experienced a reduction of meaning in work as a result of the introduction of new technologies associated with patient care record systems and the delivery of care tasks. In their study, health care workers described how caring for the elderly was diminished as a response to technical and administrative tasks taking up increasing amounts of time. Also, in a study among Norwegian home care workers, Bergschöld (2018) shows how working with a smartphone application places new demands on workers to (re)configure occupational identity to accommodate time-saving practices without neglecting the care recipients' needs. Mainly, this app, which has the intention of solving a lack of time, contributes instead to an intensification of work, because of (un)expected irregularities. Following these insights, it may be the case that employing technologies aimed at reducing physical exertion contributes to an intensification of work, where time pressure is increased and the quality of care is reduced. On the other hand, Dupret (2017) shows how nurses perform 'workarounds' on different types of standards and tests in order to deliver sufficient care, because these technologies do not work as intended and instead complicate or slow down work. Rather than viewing care workers' judgments on whether to employ particular technologies in different situations as disloyal, Dupret (2017) argues that such judgments should be understood as inscribed in professional ethics and practices, for instance as ways of making better time for providing personal care. This has earlier been framed as 'moral literacy', a professional competence enabling care workers to more openly question and judge how technologies can change the care situation and even challenge institutionally defined ethics (Krøjer \& Dupret 2015). While working around standards, tests and even technologies may contribute to better care quality based on professional judgment; working around technologies will likely contribute to higher levels of physical exertion and more unsafe work-which is another ethical problem.

In light of the above-mentioned entanglements of technologies and judgments based on ethical and professional considerations, it is important to study how the employment of technologies aimed at reducing manual handling interacts with professional and ethical values in work. Because it may be expected that the lack of effect on MSD or physical pain may be related not only to the functionalities of the technologies but also to the professional and organizational setting into which they are introduced. Without this understanding, it is likely that implementation of new technologies across the Nordic countries will continue to be unsuccessful in reducing physical exertion and MSD in care work.

In this study, we performed focus group interviews with a total of 25 care workers in elderly care and single-person interviews with seven headmasters at care homes within a larger Danish municipality. The study shows that new technologies in certain constellations may further the synergies between reducing physical exertion and occupational identities, and in other constellations may harm this relation. Based on these perspectives, the study contributes to discussions of new technologies, working environment, and identities by describing how these phenomena are entangled and must be addressed as a coherent entity if ethically consistent progress is to be made. Also, the study contributes to discussions of moral literacy and workarounds within care work by suggesting that the ability to openly judge and question both physical and ethical consequences of employing technologies could be a valuable competence for care workers in the future. 


\section{Occupational identities and new technologies in elderly care working environments}

As described above, implementation of new technologies in an organization can have an impact on occupational identities of employees. In elderly care, earlier studies have shown how occupational identities center around values of caring for patients and keeping them safe (Mueller et al. 2008; Waerness 1984). These values can be expanded to the capability to (1) recognize another's need for care, (2) take responsibility for this and decide how to respond, (3) seek to fulfill this need, and (4) engage with the response from the subject of care (Tronto 1993). Even though these idealized interactions rarely take place in a textbook-fashion and are filled with contradictions and conflicts (Tronto 2001), this identity can contribute to resistance toward new technologies either because they get in the way of the caring aspects of work (Clark \& Thompson 2015) or because these are seen as diminishing care workers' autonomy or skill discretion as has been shown in studies among other types of health care services (Berg 1997; Boonstra et al. 2004).

As with other types of identity or subjectivity, occupational identity is not to be interpreted as a static entity, since identities change both over time and in relation to contexts (Foucault 1984). Often there will, however, be some overlapping content in the presented occupational identities caused by the type of work, occupational and social conventions, physical characteristics, and traditions that are all affected by education, unions, and managerial and political relations. Within care work studies, Linda Briskin has shown how care workers frame occupational identities in relation to different occupational, economic, and political developments. In this work, it is shown how care worker identities (henceforth used interchangeably with occupational identities) have been structured around particular stances toward the concepts: (1) professionalism (revolving around autonomy, skills, expertise autonomy, and responsibility), (2) patriarchal norms (against unequal wages and professional hierarchies), (3) proletarianization (against the intensification of work, increasingly unstable terms of employment, and introduction of industrial production methods in care work), and (4) the politicization of care (revolving around care workers as guardians of patient safety, quality, and personalization of care and care as a common good) (Briskin 2012). Technologies and their purposes as such may be inscribed into different forms of occupational identities just as technologies, in many cases, contribute to the formation of occupational identities. Employing a particular technology can be an important occupational competence, which is not only the case within care work but also in other types of work (Ajslev et al. 2013; Gherardi \& Nicolini 2002).

Taking this line of thought into the study of new technologies, Halford et al. (2010) focus on a co-constructive way of thinking, where technology and people together co-create each other through mutual interaction. They argue that new technologies integrated in work not only change work tasks but also co-create the subjectivity of employees. Rather than perceiving new technologies at work as a general improvement, we should perceive technology as something changing work responsibilities, competencies, perceptions, risks, and tasks (Barley 1986; Vikkelsø 2005). Therefore, it is important to understand the meaning that is put into new technologies and to further investigate the employee's experiences with the technologies and rationalities that are described as connected with the employee's relation to the technology. 
In relation to the working environment, these relations between occupational identities and new technologies at work become increasingly important. When new technologies match employees', managers', and the organization's identities, this potentially contributes to an increased sense of meaning in work (e.g., because time is released for tasks that employees appreciate more). This can potentially decrease time pressure, which is a general challenge in elderly care work (NRCWE 2014). Paradoxically, new technologies in work may also contribute to increasing time pressure by simplifying work tasks. New technologies often contain a potential for standardization, as designers inscribe their own expectations of users' wishes, needs, and abilities (Akrich 1994). This may lead to economic reductions or an increased number of tasks, even before implementation has taken place (Clark \& Thompson 2015). The time pressure this causes may lead to both increased physical exertion and to stress (Ajslev et al. 2015). While a high number of patient transfers is associated with an increased risk of back injuries due to lifting accidents, consistent use of assistive technologies practically eliminates this increased risk (Andersen et al. 2014). Thus, use of assistive devices reducing physical exertion in this regard has the potential to ensure a safer working environment for care workers. Furthermore, the implementation of new technologies will inevitably have consequences for the ways in which the physical body of care workers is engaged in work, and therefore on the physical exertion. This is particularly the case with technologies altering physical working processes, such as person lifts, washing toilets, etc.; we know from earlier studies that reducing physical exertion in work has a positive influence on employees' experiences of pain (Andersen et al. 2007), which may in turn mean that the risk of long-term sickness absence is reduced (Andersen et al. 2011). Following these thoughts, the ways in which new technologies engage with the occupational identity among care workers and managers is important, both because this relation not only affects the way in which technologies are employed but also because the relations described have an impact on whether new technologies are reconfigured as something positive or negative for the physical exertion in work.

\section{Analytical framework}

Our analysis is based on positioning theory in an agential realist framework (Ajslev et al. 2017). This approach draws together the positioning theory approach of Davies and Harré (1991) and the agential realism of Barad (2007). Positioning theory describes how subjectivities, or in more common speech identities, are reproduced through speech acts in which people position themselves or others as having certain characteristics or belonging to certain categories or identities. In this linguistic negotiation of subject positions, participants have the option of conforming to or rejecting the offered position(s). The negotiation of subject positions is termed discursive practice by Davies and Harré (1999). Drawing on Foucauldian notions of the self, in this line of thought, subjectivity is the way in which we recognize and appreciate ourselves as having a number of more or less stable characteristics. The point of employing the concept of subjectivity is that the person or individual participates in, and is subject to, his or her own and other's expectations to the production of a coherent identity and cannot therefore individuate whatever practice he or she wishes. The subject concept emphasizes that people will always to some degree be subjected to the norms and expectations tied to the contexts 
in which they engage. For instance, when describing the characteristics of a good care worker, the care worker is at the same time describing the characteristics by which she measures herself and others. The central elements in a particular type of occupational identity can be analyzed as the characteristics associated with being a good elderly care worker or headmaster as well as the characteristics signifying the opposite of this (Berman 1999; Davies \& Harré 1999). These characteristics explicate the occupational norms one, as a worker, must engage with if one wants to be a successful colleague and employee.

The agential realist approach, inspired by the work of Karen Barad (2007), adds to this constructivist notion of identity an understanding of materiality as something not to be deconstructed into discourse. In the agential realist position, materiality is always intra-acting in our conceptions of phenomena. Therefore, accounts of materiality must be taken into consideration when performing analyses of occupational identities (Ajslev et al. 2017). For example, lifting technologies shaping physical demands in care work will to some degree also (re)configure occupational identities; because of the changed demands, care workers will somewhat reorient their opinion on what skills are needed to be a good care worker. Applying the insights from positioning theory in an agential realist framework also offers the opportunity to analyze how the characteristics of materiality, not only the identities of people, are negotiated and (re)configured through positioning. In this understanding materiality—not only speech acts—play roles in discursive practice, which are then always both discursive and material or materialdiscursive (Barad 2007). The point is that materiality plays roles by both limiting and allowing possible options for interpretation or (re)configuration of the phenomenon in question to be meaningfully put forth in material-discursive practice while never being finite. As such, it is only vaguely possible to be recognized for positioning acts that contradict spatial or practical observations that are obvious to participants in the particular material-discursive practice.

Through the agential realist framework, we perceive phenomena to be (re)configured through agential cuts consisting of (1) the observer, speaker, or researcher, (2) the apparatus (methods, tools, theories), and (3) the phenomena in question. Different agential cuts contribute to different resolutions in the phenomenon in an optical sense (e.g., the constellation of the agential cut configured through the practice of research or experience not only has a great impact on our understanding but also on the material characteristics and meanings that are created through the agential cut). Also, several agential cuts can not only be complementary (e.g., show different aspects of a phenomenon) but can also be mutually exclusive, or some cuts may offer a sharper or precise resolution in (re)configuring the phenomenon. Following this, the agential cut in a conceptual sense is both to be perceived as an epistemological concept to be applied to any type of scientific production or claim; however, it is also something that is brought into play in everyday practices (e.g., when care workers ascribe characteristics to technologies through positioning).

As we draw upon positioning theory in an agential realist framework, our analytical focus in the treatment of interview material will be aimed at identifying positioning acts that both subjects and materialities are ascribed in relation to the implementation of new technologies (in particular technologies that could reduce physical exertion in work). This means that we will examine (1) the characteristics ascribed to the good elderly care worker in relation to new technologies, and (2) the characteristics ascribed 
to lifting technologies in relation to occupational health and safety concepts such as physical exertion, pain, and influence and meaning in work. Arguably, the positioning acts performed by interview participants can be perceived as contributing to the local and daily (re)configuration of the intra-action between technology and professional values in work. However, for the sake of analytical clarity, we perceive acts of positioning as contributive to the (re)configuration of the above-mentioned phenomena at the level of our study.

\section{Methods}

The empirical material for the study was produced as part of a larger study conducted to investigate the implementation of three particular types of assistive devices (person lifts, washing toilets, and eating robots) and the implications of these technologies in relation to the exertion in work. For the study, we conducted focus-group interviews with elderly care workers and interviews with headmasters and health and safety managers at six nursing homes in Copenhagen, Denmark. Elderly care workers in Denmark are mostly trained nursing helpers or nursing assistants and have between 14 and 20 months of training, with the longest training giving qualifications for working in elderly care, hospitals, and psychiatry. Elderly care centers in Denmark also employ nurses who have 36 months of training, but nurses are typically employed in team leader or management positions. Thus, in this study, all participating interviewees at employee level were nursing helpers or assistants. In total, we interviewed 25 elderly care workers, seven headmasters, and two health and safety managers. The interview persons were all female except for two male headmasters and one male care worker. Ages ranged from 21 to 65 years. The interview persons had experience from care work ranging between 1 and 25 years.

The workplaces included in our study were recruited in collaboration with work environment consultants employed in a public organization (Work Environment Copenhagen, AMK) in the municipality of Copenhagen. The AMK consultants have an advisory function in the municipality, where they provide education for public workplaces. Our initial aim was to recruit eight nursing homes with a variety in size, location, and expected technology application based on the contextual knowledge of AMK. Eventually, two nursing homes did not want to participate in the study. Based on AMK's knowledge, these were the nursing homes with the most challenges in applying new technologies in work and were generally workplaces with some difficulties at management level. We therefore conducted our study with six nursing homes.

In our interviews with care workers, we performed focus group interviews with four to six workers, except in one case where only two workers were allowed to participate because of work tasks. We specifically requested interviews with employees who did not have specific work environment or technology roles in order to investigate the engagement with new technologies among 'ordinary' elderly care workers, not workers with particular competences. All interviews were conducted in autumn 2016 (September-December). The focus group interviews lasted approximately one and a half hours, and the management interviews lasted approximately one hour. For the analysis, each interview has been transcribed, coded, and analyzed in NVivo 11 (2015). We then selected some examples of the most profound (re)configurations regarding the intra-action of physical exertion, new technologies, and occupational identities in care work. In the analysis, we display 
these in two parts: part one mainly focusing on the positive potentials described as tied to the lifting technologies, and part two focusing on the main challenges.

\section{Analysis part one - The potential triple-win}

\section{Technology and the potential for upskilling}

Given the recent political initiatives, one might have expected that implementing and employing new technology held a prominent place in the care workers' and leaders' understanding of occupational identities and skill requirements. However, out of our 34 respondents, only three headmasters and one care worker directly mentioned new technologies as an important area of expertise. In general, a long line of characteristics known from other studies (e.g., Briskin 2012; Dybbroe 2012; Hansen 2015; Tronto 2001) were mentioned throughout our interviews as characterizing a good elderly care worker. These could be summed up as formulations about accommodation towards colleagues; health knowledge and ability to use it occupationally; empathy; communication skills in regard to colleagues, elderly, and their kin; being engaged and interested in working with elderly; keeping calm under pressure; being able to switch on and off one's 'occupational button'; and being able to create a comfortable environment for everyone. Characteristics related to technology were rarely described, and in the rare cases, it was mostly headmasters who were the ones to tie technology to the characteristics of the ideal care worker. As one headmaster described it:

\footnotetext{
The care workers we have, they have to be able to use their occupational skills, with regard to health care, therapeutically and pedagogically because we want to connect to the whole human being. [...] Also, we are bold as leaders. Last year, we tested some sensor diapers, and that is boldness [...]. And our employees need that boldness too; to try new things and dare to walk new paths. That's a good elderly care worker to me. One who knows the occupational package, dares to test things and can create a relation to the elderly. That counts for welfare technologies also. (headmaster, Case 4)
}

While not the primary focus of the ideal care worker to this headmaster, who mainly referred to known (re)configurations of care worker occupational identities focusing on empathy, practical health care, etc., the good care worker is positioned as willing to apply new technologies in work and being bold enough to try new things. Several of the interviewed headmasters position the good care worker as one capable of linking available technologies to the context of work, while at the same time expressing that this will demand more from the care worker than is demanded presently.

Through this positioning act, technology is linked to the words 'boldness' and 'dare' and thereby becomes a challenge to usual practice, as the demand for boldness or daring would not be required if the technologies did not pose a risk or challenge to something in practice. By creating this link, the headmaster draws together professionalism and technological boldness in a positive union, thereby referring to one of the areas in which care worker occupational identities have had struggles in recent years. Claiming strong professionalism has been a struggle in care work (Briskin 2012). The headmaster positions the leaders as already bold with regard to engaging with new technologies 
and in this sense accentuates a demand for care workers' abilities to (re)configure their occupational identity in order to engage with technologies. The new demands posed by technologies are further connected with the occupational skills demanded of care workers, as one headmaster described:

I'm thinking $[\ldots]$ these technologies you have to put them in a professional context for them to be positive and useful. It can be good for me as a worker, but it has to be positive for the elderly. And the more technology we get, the more it will demand from the worker. You need to know when to use one and when another. It's getting more complex. This is going to demand more from the worker than just washing and cleaning, so it's a huge demand for the future. And we need to think about this in our implementation. Otherwise, we won't harvest the benefits of this. (headmaster, Case 3)

Through the initial act of positioning in this citation, the headmaster underlines the purpose of the technologies as primarily tied to a rationality of caring for the elderly, and, secondarily, to serve the care worker. In this way, the headmaster aligns with both the rationalities of care and positions himself within the politicized care identity as defending the elderly's rights for quality care against a potentially overwhelming focus on technology and care worker wellbeing.

At the same time, the headmaster is positioning the technologies as complicating work and making new demands on the care worker, to whom usual practice is characterized as just washing and cleaning---a positioning act through which the care worker becomes deficient in the ability to handle these complexities. As such, the technologies are woven into existing identities of professionalism and the politicization of care, where the headmaster becomes the guardian of patient wellbeing; seemingly to underline the challenge of creating this change in occupational skill level and identity, but at the same time positioning headmasters and other leaders through the two final uses of 'we' as being responsible for taking these deficiencies into account in the implementation of technologies. In several cases, headmasters described the challenge of expecting a high level of technical or professional competence from the group of elderly care workers:

These are people with a one-year education, with a lot of personal issues themselves and where their social network is their colleagues. So there's little room for disagreement. And this is something we need to take into account in the working place. That it is okay to disagree. [...] You need to work with their self-efficacy, with empowerment. That needs to be the nexus of our work. (headmaster, Case 1)

In this way, the headmaster positions the good headmaster as one with special competences in leading this particular group of people in order to make them act in accordance with the expectations of them. And these three headmasters are the only ones to directly mention technology in relation to occupational competences. Only one worker actually ties the link between technology and occupational identity in an indirect fashion, describing the ability to evaluate whether to use an assistive device such as a lift or to carry out a task without:

Well it requires assistive devices. And you need knowledge about those devices, that they exist and how to use them. Then there's time, good teamwork, even though we are not that 
many in the team. It makes a great difference who you're in a team with and if there is a good team spirit - that you can help each other. [...] (care worker, Case 1)

Again, technology is positioned as demanding knowledge, time, good teamwork, and a consistent set of rules about when to apply the lifting technologies in order to work properly in the care worker service. In this way, technology is linked to professional skills and to teamwork. Thereby, the care worker ties into contested identity configurations where usage of the technology becomes dependent on having sufficient time.

In three out of our six cases, technology was not mentioned by employees or headmasters when addressing the characteristics of a good elderly care worker. While not completely nonexistent, this limited focus on the role of new technologies in the (re)configuration of occupational identity is thought provoking. As we have shown, when it was mentioned by headmasters, it was mainly because of limitations in the care worker's skills. The new technologies are (re)configured as phenomena demanding knowledge somewhat outside the current control and ability of care workers. In general, this speaks to the patriarchal/ hierarchical management forms commonly challenging the positive formation of nursing identities. This is a (re)configuration positioning the elderly care worker very low on a professional hierarchy scale, while at the same time these new demands to workers regarding the handling of more complex technologies (re)configure the new technologies as potential agents for occupational change and potential up-skilling. Headmasters and management are (re)configured as responsible for driving these potentials towards redemption.

\section{New technologies and rehabilitative care}

Even though not a central part of the political agreement of 2014, a new type of elevating bed was often described as a great assistive device among the care workers, certainly not only because it reduces physical exertion in work but also because it supports a rehabilitative approach to care:

It's not just something we request [the bed], there has to be a purpose. And clearly there is one here. Now I do not have to pull and drag him, because he is lying like that... And that's satisfying to him as well, because I don't have to pull - he can get up himself. (care worker, Case 1, focus group interview)

The care worker positions the new bed as capable of both reducing the physical exertion and of contributing to the elderly's satisfaction, freedom, happiness, and self-sufficiency. These elements entwine the rationality and politicization of caring (satisfaction, freedom, happiness) with professional elements of rehabilitative care (self-sufficiency), again underlining the potential for linking the lifting technologies with both professional identities and identities concerning the quality of care work. Another worker stated:

I see the electronic bed as a way of helping our physical exertion; you can adjust the height to clothe people in a good position without standing awkwardly. And then, one of our elderlies, we taught her to use it herself. And she is so happy about it, it sets her free, because she doesn't have to sit around and wait for us all the time. [...] Now she can get up and go to the bathroom herself. (care worker, Case 4, focus group interview) 
In several instances, workers positioned the new technologies as contributing to the meaningfulness of their work, because they could be ascribed positive characteristics in improving the elderly's self-reliance, their general wellbeing, and in reducing the workers' physical exertion. At the same time, the technology is positioned as demanding professional purpose, exactly as we saw in the headmasters' positioning acts. However, in this story, the care worker is capable of evaluating whether this purpose is present, thereby positioning herself and colleagues as competent professionals. This care worker exemplifies a wider tendency among workers to actively evaluate whether the technologies are useful in a given situation-one of the competences sought by headmasters, as shown in the previous section. This was not mentioned by workers when asked directly about the characteristics of a good worker, and thus to a potential in furthering these competences and bringing them into practice.

\section{New technologies and physical exertion in the care work}

In general, when asked how they felt about the lifting technologies, all our respondents described a positive effect of technologies that altered the physical character of work. The ceiling-mounted lifts have been under implementation for approximately 10 years and are now available in almost all nursing apartments. Only nursing homes with limited space were described as lacking these lifts. The lifts received positive reviews from care workers and headmasters in all cases; several described how work has become less physically demanding: 'You do not use your body in the same way as before, you just don't', as one care worker stated. The lifts were further praised:

The ceiling mounted lifts are one of the devices that have been implemented in our municipality in recent years. Before, we had to move heavier lifts and remove people's personal furniture, which they were so sad to lose. [...] now we can pull it straight across the ceiling. It is one of the greatest successes in the past 25 years within elderly care (care worker, Case 5)

Here, the lifts are positioned as an agency in reducing the physical exertion and as contributing to the caring rationality, since the elderly can keep their furniture. The lifts and the worker together are (re)configured as a stronger team in making sure that personal concerns can be taken into account in the care work. As earlier discussed, this is important in several care-identity (re)configurations (Briskin 2012; Halbesleben et al. 2010; Hansen 2015; Waerness 1984). Based on these rationalities, the lifts are (re)configured as a success in care work. Further, the new technology also potentially changes the workers' perception of the working environment, as exemplified by one worker:

Those lifts are a genius invention. They should, however, have mounted tracks all the way to the bathroom, so we could move people all the way instead of transferring them to a chair and then to the toilet and back again. That part is rather impractical. (care worker, Case 1)

Again, elderly care workers describe work before the lifts as markedly more physically demanding, creating a favorable positioning for the lifting technologies. Importantly 
here, the lifts are also positioned as an agent in creating a new requirement in the shape of further adaptive technologies capable of addressing the next physical challenge in work, which was a frustration to some workers. In addition, the care worker, through this act of positioning, relates to an occupational identity as competent in evaluating the values of employing the lifting technologies and their limitations. In the agential realist perspective, this is attributive to the (re)configurative capability of this new constellation of technologies and goal of care, where the care apartment with the lift allows for the discovery of a new challenge, thereby not only opening new perspectives for improvement of the physical working/caring environment but also allowing for the discovery of a new area for claiming and expanding professional expertise and status.

In one case, a headmaster went further in describing the effects of the exertionreducing technologies: 'These technologies have made it possible for some employees who have been in the profession for many years and earlier have been physically injured that they can still work. They could not have done that without these' (headmaster, Case 6). As such, the technology is also attributed an agency in maintaining older and physically challenged care workers in working for longer. The technologies were described as reducing the risk of accidents and physical deterioration as well as conferring a sense of safety to both care worker and elderly.

Altogether in this (re)configuration, the technologies become agencies capable of potentially contributing to a triple-win situation where the new technologies (1) create a room for occupational expertise and upskilling, (2) reduce the physical exertion and solve the issue of helping care workers for longer, and (3) support occupational identities of the elderly care worker as capable of rehabilitating elderly habitants and providing personal care that lives up to ethical norms.

\section{Analysis part two - Time pressure and working alone: two significant challenges of new technologies in elderly care}

Whereas the above-depicted (re)configurations may lead one to think that the new technologies are implemented with great benefit and little complication, this was actually far from the case. In particular, two issues intra-act with the rather limited direct occupational focus on new technologies in barring the new technologies from being a complete success: (1) time pressure, and (2) the new technologies' agency toward creating more solitary work.

\section{Technologies and time pressure}

In all cases, care workers describe how they do not employ these devices (particularly lifts, washing toilets, and elevating beds) because not using them may save time. In several instances, care workers described that they, for instance, do not have time to take breaks during work. This became an argument for not having the time to employ assistive devices either:

It takes a lot of time if I have to lift the elderly person back in bed while first adjusting the height of the bed and perhaps using the lift for the legs. Then it's easier to just get down on 
your knees and handle it. But it's something that you can feel in your body over the years (care worker, Case 5)

The new lifting technologies are positioned as taking time, slowing down physical care for the elderly. Also, in the final sentence here, the physical work is positioned as a threat to the body over time. The body of the worker-sensing and feeling work-is positioned as capable of identifying the physical threat. The worker in this way inscribes herself into an identity where it is more important to uphold the pace in work than to employ technological assistive devices and to care for the worker's body, because the worker's hands, knees, and feet are quick tools. Workers choose to work around the lifting technologies rather than to employ them. This ties into the politicized care worker identity, where the care worker becomes the guardian of the elderly even at the cost of sacrificing themselves (Briskin 2012; Tronto 1993). However, this can be somewhat problematic, not least because it takes time from caring for the patients, where increasing time pressure in elderly care work is already a problem (Halford et al. 2010). Also, in allowing the care workers to take care of their own bodies, this poses a problem:

We all know the limit for overloading our body and that we need to take care of it. We all know it. We can sense it, we can feel: 'this is a bad working position'. But then we have an enemy called time - and then we often skip the fence. (care worker, Case 2)

Thus, the worker positions time as an enemy, setting the pace of work and urging the worker to neglect messages from the body. In this sense, the care workers again fit their use of technology with the politicized understanding that the care worker must uphold good quality in work. In this way, several workers describe prioritizing the completion of care tasks above the care for their own bodies, even though they 'sense' bodily signals discouraging this. In addition, it was emphasized in all cases that the current improvement caused by technologies such as lifts and mechanical beds does not mean that care work is not physically demanding, it still is, to a high degree. These agential cuts also (re)configure technology as slowing down work rather than allowing for faster task completion. In a situation where time pressure is already high, this contributes to care workers neglecting their bodily signals and thereby increasing physical exertion. The time demanded for a professionally sound usage of the technologies can be seen as contradicting the organizational pressure for completing tasks as quickly as possible. In this way, several care identities are at odds with each other in the prioritization of how to conduct work. Professionalism, in employing technologies correctly and for a meaningful and good purpose, is positioned against timely care quality for the elderly.

\section{Working alone and efficiency agency}

In several cases, care workers addressed the efficiency agency of the new technologies:

With these new lifts and turning systems you know. Before, you were two at a task. Today, you're alone. So we're alone a lot more, not as much partnership as before. So you have to handle the elderly and the tasks yourself. Apart from being alone, this also means that you have to coordinate, because sometimes it takes two people to move an elderly person, even 
with the lift. And then you have to wait until a colleague has time. Then you lose precious time, and often you end up doing it alone even though the job is too heavy because you have three more elderly to care for in the morning. (care worker, Case 2)

Whereas earlier we saw a number of positive positions ascribed to the lifting technologies, here the lifts and turning systems are positioned as contributing to more working alone, less partnership with colleagues, complicating work, and increasing the need for coordination. Here, we find some of the specific new professional demands posed by the technologies. Again, the 'time enemy' becomes entwined in this (re)configuration where the intra-actions of these agencies become rationalities for not caring for the worker's body. In this sense, the technologies become part of what Briskin (2012) describes as the proletarianization issue, challenging care work. Not only are the technologies hard to use under the current time pressure, but they also contribute to increasing this pressure. In several cases, the lifts are described as allowing workers to transfer patients alone, whereas earlier practice would demand two workers for an elderly transfer situation.

\begin{tabular}{|c|c|}
\hline Interviewer: & 'So what are your rules on patient transfers?' \\
\hline Care worker 1: & 'Well, the rule is that you don't lift alone.' \\
\hline Care worker 2: & 'Both for our safety and the elderly person's.' \\
\hline Care worker 1: & $\begin{array}{l}\text { 'Exactly, I mean, with the ceiling mounted lifts, it's even safer than } \\
\text { with the standing lifts, which can break. But you know, because of the } \\
\text { understaffing, you don't stand there and call and wait for a colleague } \\
\text { who can't come immediately. You just don't' (care workers, Case 1) }\end{array}$ \\
\hline
\end{tabular}

Here, the lifts are initially positioned as contributing to safety for both the elderly and workers. However, understaffing and coordination demanded by the technologies are a real threat to which the care worker is positioned as powerless. Hence, instead, they commence the more physically demanding and risky work. A competence then becomes working alone and making correct decisions regarding transferring the elderly while under pressure to work fast. As we just saw, this often leads to workers neglecting caring for their own bodies. A colleague in the focus group interview supported this by saying: 'It's become like, we have such nice assisting devices that it increases the focus on effectiveness. I mean, we have to be more effective because we have such useful assisting devices' (care worker, Case 2)-in this way, positioning the technology as an agency contributing to increased efficiency demands. As this shows, the new technologies are (re)configured as playing an agential role in changing the content of work toward both allowing more working alone, which may lead to risks of both increased physical exertion and violence (Brennan 2010). At the same time, it creates new demands for occupational evaluation of when to apply technologies and for coordinating work with colleagues. In several cases like the one above, the potential of technology for allowing solo work counteracts its potential for reducing physical exertion and the risk for accidents by urging care workers to handle situations alone. The technologies are further (re)configured as increasing the demands for effectiveness as part of work. In this way, the reliance on technologies to ensure increased efficiency may increase physical exertion as well as the risk of lifting accidents at work. Indeed, the technologies bring along the time pressure, which works directly against their own time demand. 
I do fear that it will be like, 'All right, we will just take some more technologies and then you can work alone, and get those elderly people done quickly.' I mean it cannot be the main priority. There needs to be a balance. We must use these new technologies because it's a good idea for this elderly person or for the situation. (headmaster, Case 2)

The headmaster is somewhat negative about the prospect that employees may be replaced by technology, both because it may mean more working alone and more human-technology cooperation. This positioning of new technologies in a generalized form questions the potentials of the technologies for reducing physical exertion and risks in the working environment. In the places where the technologies gain these characteristics, they work against vital parts of the occupational identities among both care workers and headmasters. At the same time, they contribute to an increase in time pressure and working alone, which may more likely be counterproductive to decreasing the risk of accidents and physical strain.

Altogether, this constellation of care worker and technologies under the current regime of technological implementation is a version of worker/tech that works under time pressure, disregards the body, upholds the pace, experiences an increased need for working alone and for coordination, and experiences increased physical exertion and ethical dilemmas in regard to the quality of care for the elderly.

\section{Concluding discussion}

As the analysis depicts, the intra-actions among new technologies in elderly care, occupational identities, and physical exertion make a complicated field of study. In the initial part of the analysis, we show how the occupational identity among care workers and managers to a very limited extent encompasses characteristics associated with new technologies in work as a central competence. This means that only a few care workers and managers explicitly describe the processes of getting to know, evaluate, implement, and employ new technologies as relevant competencies. The headmasters linking occupational identity to the employment of new technologies underline a potential for improving this relationship. The only worker who explicitly (re)configures knowledge and ability to employ assistive devices as professional competences creates a link between certain organizational conditions as the background for effectively creating this link. Interestingly, the conditions this worker mentions such as 'sufficient time', 'knowledge', and 'uniform rules' are somewhat related to the challenges described later on in the analysis. The headmasters position themselves as important agencies in ensuring proper employment of the new technologies. They can assist in improving the knowledge, boldness, and skill needed among care workers, and they can guard the elderly from an overwhelming focus on technology or the working environment, which fits nicely within care workers' occupational identity but is at the same time somewhat condescending regarding worker professionalism. This condescending attitude from management toward the care workers is not a new thing, but is a longstanding issue (Briskin 2012).

The mechanical lifting technologies such as washing toilets and beds used with the proper amount of time based on appropriate professional evaluation are in general (re)configured as reducing workers' experience of physical exertion and risk of workrelated injuries. In fact, both care workers and headmasters (re)configure a potential 
triple-win situation where the new technologies contribute to (1) potential professional upskilling, (2) reducing physical exertion and thereby maintaining the ability to work for longer, and (3) contribute to rehabilitative and personalized caring practice. Furthermore, we show how care workers, in engaging with the new technologies, also begin to discover further areas for technological innovation capable of assisting them in physically demanding care work. This engagement attributes the technology as contributing to a (re)configuring of the worker toward being a technological innovator. This version of occupational identity was not something we saw when discussing the characteristics of the ideal care worker directly, and it also somewhat poses a contradiction to the relation between care worker and technology depicted by the headmasters. Perhaps furthering these capacities could be a way of creating the engagement and upskilling that headmasters seek, but in a less condescending way.

Had all been well, this would be the end of the discussion. However, the potential triple-win situation is widely challenged by a number of intra-acting phenomena. Primarily, two organizational mechanisms are obstacles of the triple-win: the time pressure and the efficiency agency of the new technologies. Time pressure becomes an obstacle because employing technologies to assist in lifting or transferring patients often takes more time than doing it manually. Since the care workers have to complete care for a number of elderly people, this time spent using assistive devices compromises an important aspect of occupational identity, namely empathic communication and creating a comfortable environment for the elderly. Instead of employing the technologies that could reduce the physical exertion, the care workers describe that they have to handle physically demanding tasks by hand in order to maintain pace and quality in care.

The efficiency agency can be interpreted as the materialization of a political strategy where new technologies are introduced with a built-in economic reduction of funding. This means that these new technologies are also, among the care workers, (re)configured as creating an expectation of increased efficiency. This is also apparent in the political agreement, as initially mentioned. The new technologies have become an agency removing resources from the elderly care sector-both workers and managers experience this. Specifically, this has had the effect of creating more working alone and further increasing time pressure for the care workers. To a high degree, this reproduces the tendencies described in Bergschöld's (2018) study of Norwegian home care workers, albeit with a different type of technology. This suggests that the issues described in this study may be relevant for implementations of new lifting technologies across the Nordic countries. As such, it is no surprise that some resistance toward the technologies is expressed; after all, based on these characteristics, they do in their current (re)configuration contribute to what Briskin (2012) terms the proletarianization of care work.

The increased need for working alone carries with it risks of increased physical exertion and of experiencing violence at work (Brennan 2010), essentially because the care worker is more often alone in handling emotionally stressful situations and manual lifting. Furthermore, it creates an increased demand for coordinating work among colleagues so that tasks requiring two people can be carried out. Many care workers, however, underline the fact that they instead carry out these tasks alone in order to save time, to maintain flow in their work, and to make sure the needs of the elderly are met. Often, they describe skipping usage of the technologies altogether because they feel too busy. Again, they perform workarounds (Dupret 2017). This is somewhat in accordance with occupational identities of good care work (Briskin 2012; Tronto 1993), but it is certainly 
counterproductive to taking care of the care worker's body and safety, since for instance, lifting heavy elderly clients alone or working at a faster pace has long been regarded as the main challenges for the physical working environment in the field (Konring et al. 2018).

This shows that new technologies in certain constellations can further the synergy between occupational identity and physical environment as in 'the rehabilitating care worker with mechanical assistive devices' and in other constellations may damage this relationship: 'The alone-working care worker who has no time to use assistive devices and neither to provide the care she wants'. Also, we find a (re)configuration of headmasters who can contribute even further than is presently the case to bringing forth and improving care worker expertise regarding the evaluation and proper employment of lifting technologies.

Deciding how to handle these matters are issues for legislators, managers/headmasters, and unions throughout the Nordic countries, where the focus on welfare technologies is shared (Kamp et al. 2019). This calls for thorough ethical discussions. Is it good or bad to replace a human workforce with technologies? It can be good if we solve the challenges concerning physical exertion and safety risks and fill both elderly people's lives and the working life of care workers with meaningful activities, such as reducing the loneliness of elderly people and making sure they are comfortable with technologies.

If not, if the agency of technologies toward accelerating work pace, increasing working alone, and taking time from the tasks care workers appreciate, then we are moving care work in an unsustainable direction—not only for care workers' physical health but for the elderly as well. It is apparent that the technologies we have investigated have a number of agencies pulling their employment and care work in different directions. Establishing a view of these and thereby offering the opportunity for ethical concern is one of the main contributions of this study. This suggestion to consider the physical exertion in the employment of new technologies can be seen as contributive to the moral literacy concept introduced by Krøjer and Dupret (2015) as a professional competence in care work enabling care workers to more openly question and judge how technologies can change the care situation and even challenge institutionally defined ethics. It is necessary to make these considerations from an ethical perspective, and not only an economic one, because this has a great impact on how occupational identity and the character of care work will be shaped in the future. If management is oriented toward getting work done as cheaply and quickly as possible, care workers will adjust to this and practice the same rationalities. If management is oriented toward creating the healthiest and most meaningful elderly- and working life in elderly care, care workers will orient themselves accordingly.

\section{References}

Ajslev, J. Z. N., Lund, H. L., Møller, J. L., Persson, R., Andersen, L. L. (2013). Habituating pain: Questioning pain and physical strain as inextricable conditions in the construction industry, Nordic Journal of Working Life Studies 3: 195-218.

Ajslev, J. Z. N., R. Persson and L. L. Andersen (2015). Associations between wage system and risk factors for musculoskeletal disorders among construction workers. Pain Research and Treatment. 513903. 
Ajslev, J. Z., Møller, J. L., Persson, R., Andersen, L. L. (2017). Trading health for money: agential struggles in the (re)configuration of subjectivity, the body and pain among construction workers, Work Employment and Society 31(6): 887-903.

Akrich, M. (1994). The De-Scription of Technical Objects, in Bijker and Law. In Shaping Technology/Building Society. Cambridge, MA: MIT Press: 205-224.

Andersen, L. L., Clausen, T., Mortensen, O. S., Burr, H., Holtermann, A. (2012). A prospective cohort study on musculoskeletal risk factors for long-term sickness absence among healthcare workers in eldercare, Int Arch Occup Environ Health 85: 615-622.

Andersen, L. L., Burdorf, A., Fallentin, N., Persson, R., Jakobsen, M. D., Mortensen, O. S., Clausen, T., Holtermann, A. (2014). Patient transfers and assistive devices: prospective cohort study on the risk for occupational back injury among healthcare workers, Scand J Work Environ Health 40: 74-81.

Andersen, J. H., Haahr, J. P., and Frost, P. (2007). Risk factors for more severe regional musculoskeletal symptoms: a two-year prospective study of a general working population, Arthritis \& Rheumatism 56(4): 1355-1364.

Barad, K. (2007). Meeting the Universe Halfway - Quantum Physics and the Entanglement of Matter and Meaning, Durham \& London: Duke University Press.

Barley, S. R. (1986). Technology as an occasion for structuring: evidence from observations of CT scanners and the social order of radiology departments, Administrative Science Quarterly 31(1): 78-108.

Berg, M. (1997). Rationalizing Medical Work: Decision Support Techniques and Medical Practices, The MIT Press.

Bergschöld, J. M. (2018). When saving time becomes labor: time, work, and technology in homecare, Nordic Journal of Working Life Studies 8(1).

Berman, L. (1999). Positioning in the Formation of a 'National Identity.' In Positioning Theory, by Rom Harré and Luk van Langenhove (Eds.), Oxford, UK: Blackwell Publishers Ltd.

Boonstra, A., D. Boddy, and M. Fischbacher (2004). The limited acceptance of an electronic prescription system by general practitioners: reasons and practical implications, New Technology, Work and Employment 19(2): 128-144.

Brennan, W. (2010). Safer lone working: assessing the risk to health professionals, British Journal of Nursing (Mark Allen Publishing) 19(22): 1428-1430.

Briskin, L. (2012). Resistance, mobilization and militancy: nurses on strike, Nursing Inquiry 19(4): 285-296.

Clark, I., and A. Thompson (2015). Healthcare assistants: distributional losses as a consequence of NHS modernisation? New Technology, Work and Employment 30(3): 209-221.

Danmarks Statistik (2017). Befolkningens Udvikling 2016 [Vital Statistics 2016], København $\varnothing$ : Danmarks Statistik.

Davies, B., and R. Harré (1999). Positioning and personhood, Positioning Theory: Moral Contexts of Intentional Action: 32-52.

Dupret, K. (2017). Working around technologies—invisible professionalism? New Technology, Work and Employment 32(2): 174-187.

Dupret, K. and B. Friborg (2018). Workarounds in the Danish Health Sector - from tacit to explicit innovation, Nordic Journal of Working Life Studies 8(S3).

Dybbroe, B. (2012). Work identity and contradictory experiences of welfare workers in a life-history perspective, Forum Qualitative Sozialforschung / Forum: Qualitative Social Research 13(3).

Foucault, M. (1983). The subject and power. In The Essential Foucault (Rabinow, P. and Rose, N. (Eds.)), The New Press: 126-144.

Foucault, M. (1984). The Ethics of the Concern of the Self as a Practice of Freedom. In The Essential Foucault (Rabinow, P. and Rose, N. (Eds.)), The New Press: 25-42. 
Gherardi, S. and D. Nicolini (2002). Learning the trade: a culture of safety in practice, Organization 9(2): 191-223.

Greenhalgh, T., G. Robert, F. Macfarlane, P. Bate, and O. Kyriakidou (2004). Diffusion of innovations in service organizations: systematic review and recommendations, The Milbank Quarterly 82(4): 581-629.

Grint, K., and S. Woolgar (2007). The Machine at Work, Polity Press.

Halbesleben, J. R. B., G. T. Savage, D. S. Wakefield, and B. J. Wakefield (2010). Rework and workarounds in nurse medication administration process: implications for work processes and patient safety, Health Care Management Review 35(2): 124-133.

Halford, S., A. Obstfelder, and A. T. Lotherington (2010). Changing the record: the inter-professional, subjective and embodied effects of electronic patient records, New Technology, Work and Employment 25(3): 210-222.

Hansen, A. M. (2015). Rehabilitating Elderly Bodies and Selves - New Forms of Care Work, Professional Identity and Status in Rehabilitative Home Care, Roskilde University.

Jakobsen, M. D, B. Aust, J. Dyreborg, P. Kines, M. B. Illum, and L. L. Andersen (2016). Participatory organizational intervention for improved use of assistive devices for patient transfer: study protocol for a single-blinded cluster randomized controlled trial, BMC Musculoskeletal Disorders 17(1): 501-512.

Kamp, A., A. Obstfelder, and K. Andersson (2019). Welfare Technologies in Care Work, Nordic Journal of Working Life Studies 9(5).

Krøjer, J. and K. Dupret (2015). Moral literacy in technological care work, Ethics and Social Welfare 9(1): 50-63.

Local Government Denmark (2017). Slutmåling - det kommunale program for distribution af velfærdsteknologier 2014-2016 [Final Measurement - the municipal programme for distribution of welfare technologies 2014-2016]. Weidekampsgade 10, Copenhagen: Local Government Denmark.

Modig, A. (2012). Välfärdsteknologi inom äldreomsorgen. En kartläggning av samtliga Sveriges kommuner [Welfare Technology Within Elderly Care. A Survey of all the Swedish Municipalities], Hjälpmedelsinstitutet.

Mueller, F., R. Valsecchi, C. Smith, J. Gabe, and M. A. Elston (2008). 'We Are Nurses, We Are Supposed to Care for People': Professional Values among Nurses in NHS Direct Call Centres, New Technology, Work and Employment 23(1-2): 2-16.

NOU (2011). Official Norwegian Reports NOU 2011: 11. Innovation in the Care services (Chapter 1, 2 and 3), Oslo: Norwegian Ministry of Health and Care Services.

NRCWE (2014). Danskernes Arbejdsmiljø 2014 [work environment in Denmark 2014]. Copenhagen, Denmark: National Research Centre for the Working Environment.

Tronto, J. (1993). Moral Boundaries: A Political Argument for an Ethic of Care, New York: Routledge.

Tronto, J. (2001). An Ethic of Care. In Voices of Community Care: Ethics, Aging and Caring Practices, by Hirschmann, N. J. and Di Stefano, C. (Eds.), New York: Westview Press: 139-156.

Verbeek, J. H., KP. Martimo, P. Paul, F. M. Kuijer, et al. (2012). Proper manual handling techniques to prevent low back pain, a Cochrane Systematic Review, Work (Reading, Mass.) 41 Suppl 1: 2299-2301.

Vikkelsø, S. (2005). Subtle redistribution of work, attention and risks: electronic patient records and organizational consequences, Scandinavian Journal of Information Systems 17(1): 3-30.

Waerness, K. (1984). The rationality of caring, Economic and Industrial Democracy 5(2): $185-211$. 